\title{
Simple non-basic solution route for the preparation of zinc oxide hollow spheres
}

\author{
Ashoka Siddaramanna ${ }^{\mathrm{a}}$, Kumarappa Veerappa Thipperudraiah ${ }^{\mathrm{b}}$, \\ Gujjarahalli Thimmanna Chandrappa a,* \\ a Department of Chemistry, Central College Campus, Bangalore University, Bangalore 560001, India \\ ${ }^{\mathrm{b}}$ Department of Physics, Ambedkar First Grade College, Bangalore 560008, India
}

\section{A R T I C L E I N F O}

\section{Article history:}

Received 23 August 2011

Received in revised form

25 January 2012

Accepted 13 February 2012

Available online 3 March 2012

\begin{abstract}
A B S T R A C T
Despite considerable efforts undertaken in a rapidly developing area of materials research, controlled synthesis of nanostructured $\mathrm{ZnO}$ is still a matter of intensive research. Herein, we report a facile base free approach for the fabrication of nanostructured $\mathrm{ZnO}$ hollow spheres. In the synthesis, ethylene glycol has been introduced as solvent and crystal-growth modifier and zinc acetate has been used as zinc precursor and also a source of soft template. $\mathrm{ZnO}$ nanoparticles of diameter $\sim 25 \mathrm{~nm}$ are assembled into highly regular hollow spheres. The powder X-ray diffraction (XRD), Raman spectroscopy, Fourier transform infrared (FTIR), scanning electron microscopy (SEM), transmission electron microscopy (TEM), selected area electron diffraction (SAED), energy dispersive X-ray spectroscopy (EDS), photoluminescence (PL) and UV-visible spectroscopy have been used to characterize the crystal structure, morphology, composition and optical properties. Powder XRD pattern of ZnO confirms the formation of the wurtzite structure. Presence of oxygen deficiency in the prepared $\mathrm{ZnO}$ product is revealed by Raman and EDS studies. Strong emission at $422 \mathrm{~nm}$ with three weak emissions at 400, 484 and $529 \mathrm{~nm}$ were observed by PL spectrum. The growth mechanism for the formation of $\mathrm{ZnO}$ hollow spheres has been discussed on the basis of the growth model for the polar $\mathrm{ZnO}$ crystals.
\end{abstract}

(c) 2012 Elsevier B.V. All rights reserved.

\section{Introduction}

Nowadays, hollow spheres of nanometer to micrometer dimensions have attracted great interest because of their low density, high surface-to-volume ratio, large surface area and also their ability to interact with ions not only at the surface but also throughout the bulk of the materials [1]. Because of these excellent properties, hollow structured microspheres are widely used as artificial cells, catalysts, fillers, and for controlled release of drugs, dyes, cosmetics and inks [2-7]. A significant number of inorganic hollow structured materials such as $\mathrm{CuO} / \mathrm{Cu}_{2} \mathrm{O}, \mathrm{TiO}_{2}, \mathrm{SnO}_{2}, \mathrm{Fe}_{2} \mathrm{O}_{3}, \mathrm{Co}_{3} \mathrm{O}_{4}, \beta-\mathrm{Ni}(\mathrm{OH})_{2}, \alpha-\mathrm{MnO}_{2}, \mathrm{CuS}$, $\mathrm{Sb}_{2} \mathrm{~S}_{3}, \mathrm{CdMoO}_{4}, \mathrm{ZnWO}_{4}$ [8-19] and $\mathrm{ZnO}[20-22]$ have been reported. $\mathrm{ZnO}$ hollow structured microspheres were usually synthesized through thermal evaporation process [23-27] and hydrothermal method [20,28-30]. Thermal evaporation process usually involves the disadvantages related to requiring special equipment, high temperature $\left(>500{ }^{\circ} \mathrm{C}\right.$ ) and vacuum condition. In hydrothermal method, templates were generally employed for creating hollow structures. Most commonly used templates are spherobacterium, sulfonated polystyrene, pickering emulsion, surfactant vesicles and liquid droplets [20,28-32]. This template dependent hydrothermal method always requires extremely complicated synthetic procedures

\footnotetext{
* Corresponding author. Tel.: +91802296 1350.

E-mail address: gtchandrappa@yahoo.co.in (G. Thimmanna Chandrappa).
}

such as fabrication of templates, introduction of surface functional groups, deposition of the target material and post removal of the templates. The use of templates therefore, results in high cost, low product yield and time consuming synthesis procedure. Recently, template free hydrothermal method is also reported for the preparation of hollow structured $\mathrm{ZnO}$ microspheres [33]. However, inorganic or organic bases are commonly used in this approach. Therefore, a direct fabrication of hollow structured $\mathrm{ZnO}$ microspheres at low cost remains a challenge for the materials scientists. In recent years, base free approaches have been reported for the fabrication of $\mathrm{ZnO}$ nanoparticles [34], flower [35] and nanorods [36] but not for the fabrication of $\mathrm{ZnO}$ hollow structured microspheres.

In this paper, we demonstrate a novel low temperature and template/base free approach to synthesize large scale hollow structured $\mathrm{ZnO}$ microspheres. The key point of the successful realization is that we use an ethylene glycol to control the growth rate of $\mathrm{ZnO}$ crystals and water bubbles as source of soft template for the formation of microspheres with hollow interior.

\section{Experimental}

\subsection{Materials preparation}

Analytical pure grade chemicals were used without further purification. In a typical solvothermal synthesis, $0.5 \mathrm{~g}$ of zinc 
acetate was dissolved in $13 \mathrm{ml}$ of ethylene glycol taken in a Teflon lined stain less autoclave and stirred for $20 \mathrm{~min}$. The obtained clear solution was kept at $160{ }^{\circ} \mathrm{C}$ for $1 \mathrm{~d}$. After the solvothermal process, the autoclaves were cooled to an ambient temperature and the resultant white solid was extracted by centrifugation. Then the obtained solid product was washed with distilled water followed by ethanol and finally dried at $70{ }^{\circ} \mathrm{C}$ for $2 \mathrm{~h}$.

\subsection{Materials characterization}

Powder X-ray diffraction data were recorded on a X'pert PRO PANalytical X-ray diffractometer with graphite monochromatized $\mathrm{Cu} \mathrm{K} \alpha$ radiation. The morphology of the product was examined by a JEOL-JSM-6490 LV scanning electron microscope and a CM12 Philips transmission electron microscope equipped with EDS (Kevex Sigma TM Quasar, USA). Raman spectrum was recorded at room temperature with a confocal laser micro-Raman spectrometer (LABRM-HR). The absorption spectrum was recorded using a Shimadzu visible spectrometer (UV-3101) at room temperature. Photoluminescence studies were carried out on a Perkin-Elmer LS-55 luminescence spectrometer using Xe lamp with an excitation wavelength of $325 \mathrm{~nm}$ at room temperature.

\section{Results and discussion}

\subsection{Powder X-ray diffraction}

The powder XRD patterns of the solvothermally derived $\mathrm{ZnO}$ products obtained at $120^{\circ} \mathrm{C}, 140{ }^{\circ} \mathrm{C}$ and $160{ }^{\circ} \mathrm{C}$ for $1 \mathrm{~d}$ are shown in Fig. 1. The diffraction pattern obtained at $120^{\circ} \mathrm{C}$ (Fig. 1(a)) agrees well with that of layered hydroxide of zinc acetate (LHZA) having features of lamellar compounds related to brucite-type layers [37]. The LZHA exhibited layered structures as evidenced from their X-ray diffraction (XRD) patterns, which showed intense $\left(\begin{array}{lll}0 & 0 & 1\end{array}\right)$ diffraction peaks in the low angle range and asymmetric reflections in the range of high angles. Such features can be explained on the basis of stacking order of brucite-like sheets parallel and equidistant but twisted and/or translated

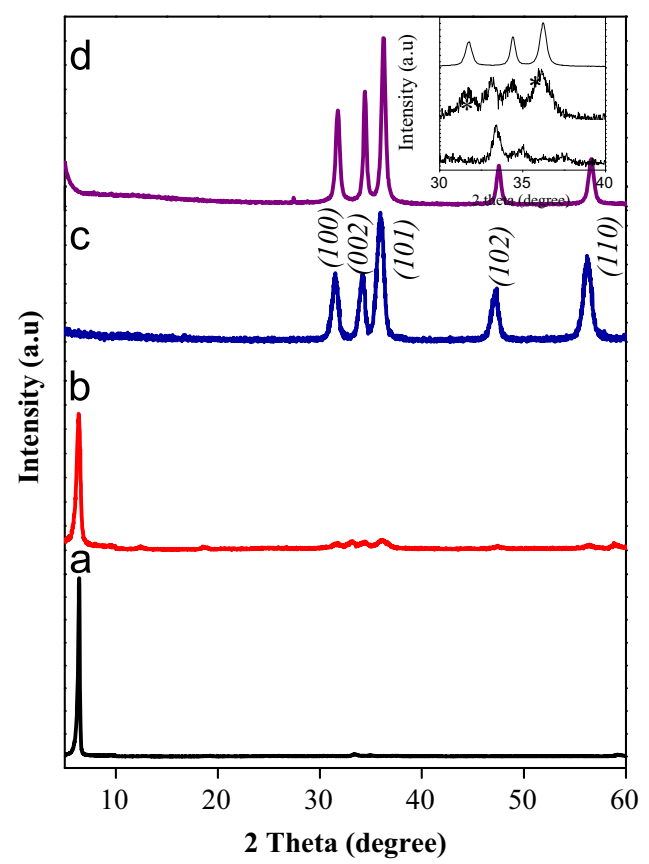

Fig. 1. Powder XRD pattern of the $\mathrm{ZnO}$ product prepared at (a) $120^{\circ} \mathrm{C}$, (b) $140{ }^{\circ} \mathrm{C}$, (c) $160{ }^{\circ} \mathrm{C}$ and (d) $180^{\circ} \mathrm{C}$ for $1 \mathrm{~d}$. against each other [38-40]. The product obtained at $140{ }^{\circ} \mathrm{C}$ (Fig. 1(b)) represents a mixture of both LHZA and ZnO (marked by $\left.{ }^{*}\right)$. Whereas, phase pure $\mathrm{ZnO}$ can be obtained when the temperature increases to $160{ }^{\circ} \mathrm{C}$ and $180{ }^{\circ} \mathrm{C}$ (Fig. 1 (c) and (d)). All the diffraction peaks of the XRD pattern can be assigned to the hexagonal phase of wurtzite $\mathrm{ZnO}$ structure with lattice constants $a=0.3249 \mathrm{~nm}$ and $c=0.5206 \mathrm{~nm}$, which is in good agreement with the reported literature values of $\mathrm{ZnO}$ (JCPDS 36-1451).

\subsection{Scanning electron microscopy}

The SEM images of the products prepared at $120{ }^{\circ} \mathrm{C}, 140^{\circ} \mathrm{C}$, $160{ }^{\circ} \mathrm{C}$ and $180^{\circ} \mathrm{C}$ for $1 \mathrm{~d}$ are shown in Fig. 2. The product obtained at 120 C shows wire-like morphology (Fig. 2(a)). The product prepared at $140{ }^{\circ} \mathrm{C}$ (Fig. 2(b)) exhibits a micrometer sized spheres with uniform diameter. The diameter of the spheres is found to be in range of $1-1.5 \mu \mathrm{m}$. It is clear that lots of microspheres with hollow interior were observed at $160{ }^{\circ} \mathrm{C}$ (Fig. 2(c)). Close examination reveals that the surface of the spheres is not smooth, indicating that the spheres are made by the self-assembly of small $\mathrm{ZnO}$ nanoparticles. The $\mathrm{ZnO}$ product prepared at $180{ }^{\circ} \mathrm{C}$ (Fig. 2(d)) also shows the existence of hollow spheres besides the nanoparticles.

The effect of solvothermal time on the formation of self assembled hollow spheres is investigated. It is also found that the formation of $\mathrm{ZnO}$ hollow spheres has been influenced significantly by the solvothermal time. The products prepared at $160{ }^{\circ} \mathrm{C}$ for 3 and $6 \mathrm{~h}$ exhibit irregular morphologies as shown in Fig. 3(a) and (b). Whereas, the product prepared at $160{ }^{\circ} \mathrm{C}$ for $12 \mathrm{~h}$ shows hollow spheres (Fig. 3(c)).

\subsection{Transmission electron microscopy}

Fig. 4 shows the TEM image and corresponding SAED pattern taken on the surface of the $\mathrm{ZnO}$ hollow spheres prepared at $160{ }^{\circ} \mathrm{C}$ for $1 \mathrm{~d}$. The $\mathrm{ZnO}$ hollow spheres were composed of nanoparticles with a diameter of $\sim 25 \mathrm{~nm}$. All of these nanoparticles are single crystalline in nature and can be indexed as the hexagonal $\mathrm{ZnO}$ phase as evidenced from the SAED pattern (inset of Fig. 4). This result is consistent with the XRD results.

\subsection{Energy-dispersive X-ray spectroscopy}

The chemical purity of $\mathrm{ZnO}$ as well as its stoichiometry was investigated using EDS analysis. The EDS spectrum (Fig. 5) clearly indicates that the hollow spheres are composed of $\mathrm{Zn}$ and $\mathrm{O}$. The $\mathrm{Cu}$ peak arises from the copper grid. Quantitative elemental analysis reveals that the atomic ratio of $\mathrm{Zn:O}$ is 56.2:43.8, indicating the presence of oxygen deficiency, which might have been caused during the rapid formation of $\mathrm{ZnO}$ under solvothermal condition. This is confirmed by both Raman and photoluminescence studies.

\subsection{Raman spectroscopy}

ZnO crystal exhibits the hexagonal wurtzite structure, which belongs to the space group $\mathrm{C}_{6 \mathrm{~V}}$ [41]. According to the selection rules of phonon resonance modes, Raman-active modes for wurtzite $\mathrm{ZnO}$ are $\mathrm{A}_{1}+2 \mathrm{E}_{2}+\mathrm{E}_{1}$ [42]. The $\mathrm{A}_{1}$ and $\mathrm{E}_{1}$ modes are polar and can be split into the transverse optical (TO) and longitudinal optical (LO) phonon modes. The $E_{2}$ mode is nonpolar optical phonon mode that is composed of two modes with a low and a high frequency. Fig. 6 demonstrates the room temperature Raman spectrum of the $\mathrm{ZnO}$ hollow spheres in the wave number range $50-700 \mathrm{~cm}^{-1}$. Vibration peaks can be clearly observed at $100 \mathrm{~cm}^{-1}, 332 \mathrm{~cm}^{-1}$ and $440 \mathrm{~cm}^{-1}$. The two strong peaks at 

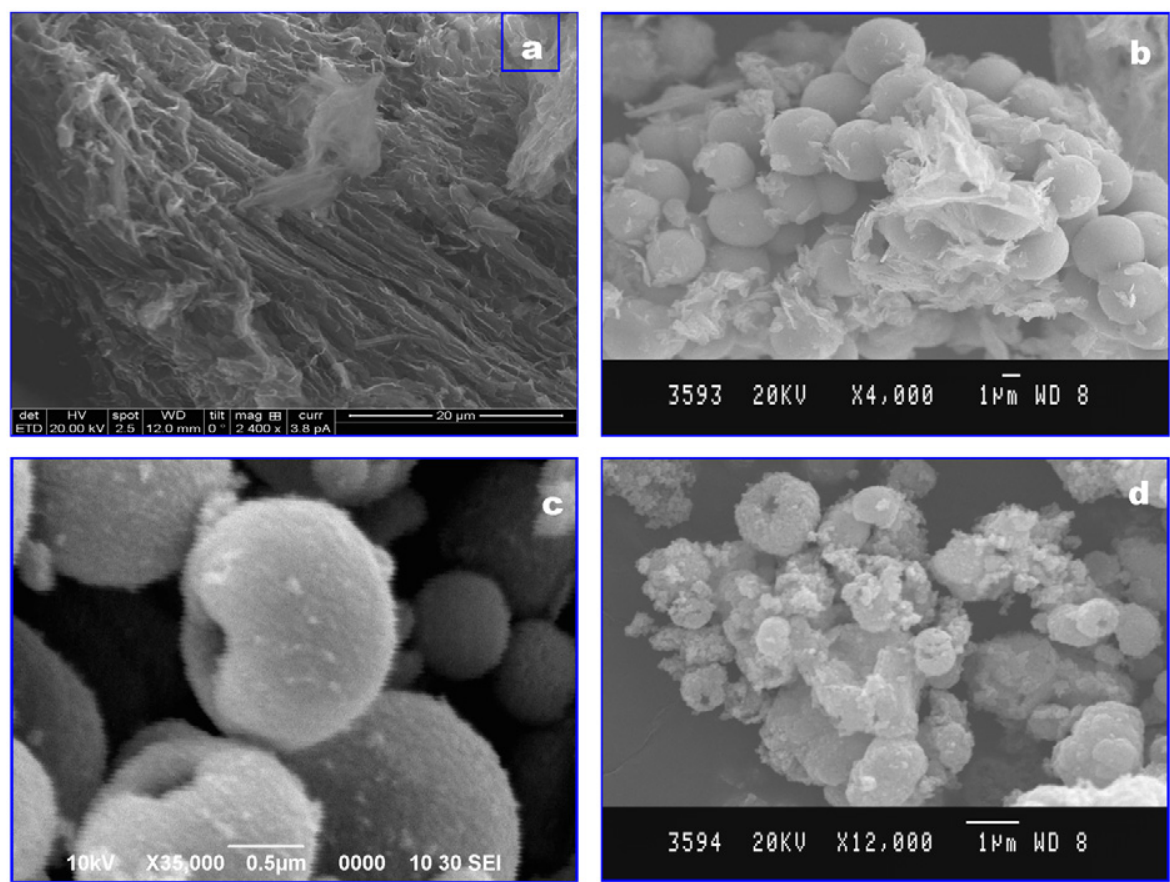

Fig. 2. SEM images of the $\mathrm{ZnO}$ products prepared at (a) $120^{\circ} \mathrm{C}$, (b) $140{ }^{\circ} \mathrm{C}$, (c) $160{ }^{\circ} \mathrm{C}$ and (d) $180{ }^{\circ} \mathrm{C}$ for $1 \mathrm{~d}$
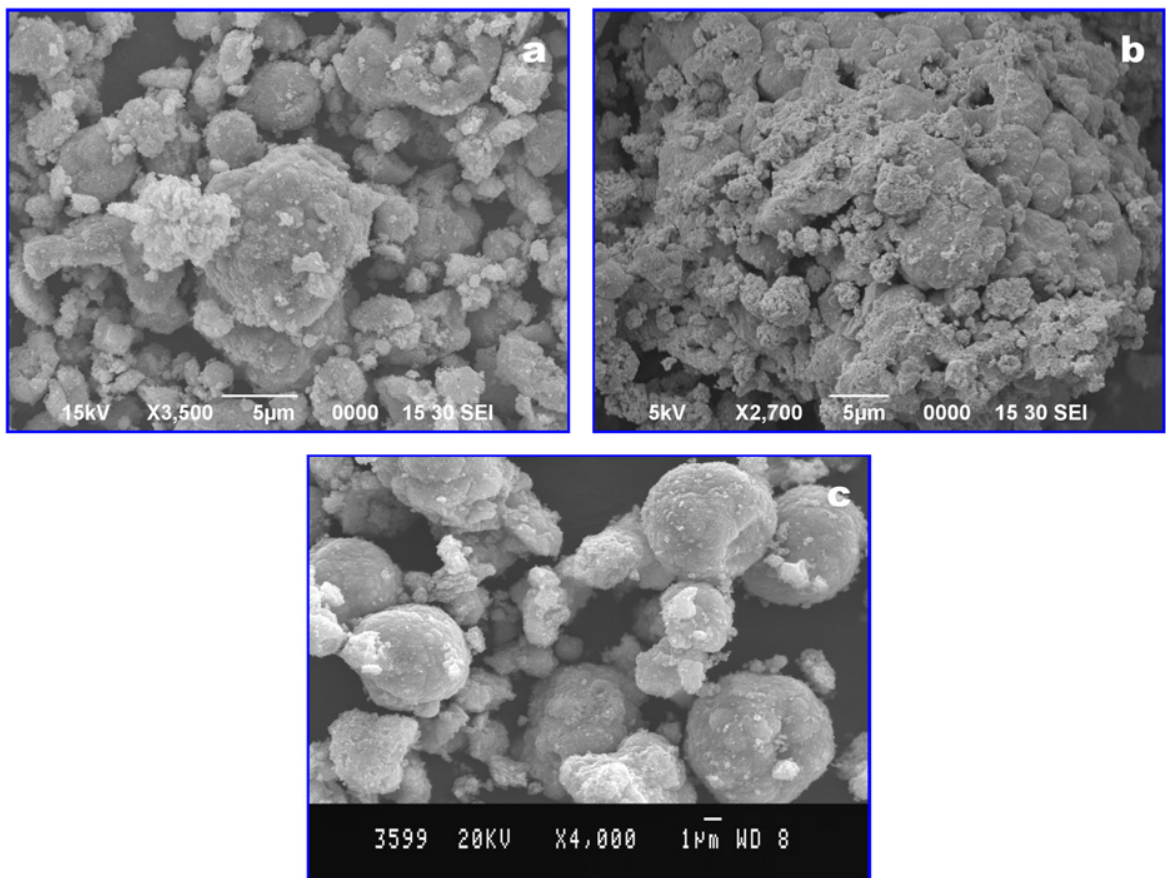

Fig. 3. SEM images of the $\mathrm{ZnO}$ products prepared at $160^{\circ} \mathrm{C}$ for (a) 3 , (b) 6 and (c) $12 \mathrm{~h}$

$100 \mathrm{~cm}^{-1}$ and $440 \mathrm{~cm}^{-1}$ can be assigned to the two non polar optical phonon $\left(\mathrm{E}_{2}\right)$ modes of the $\mathrm{ZnO}$ hollow spheres at low and high frequency respectively, which are associated with oxygen deficiency. The peak at $332 \mathrm{~cm}^{-1}$ is attributed to the $2 \mathrm{E}_{2}$ mode. A strong intensity of the $\mathrm{E}_{2}$ modes implies that the $\mathrm{ZnO}$ hollow spheres are severely oxygen deficient [43].

\subsection{Optical properties}

PL study is an effective technique to evaluate both $\mathrm{ZnO}$ defects and its optical property available as a photonic material. Fig. 7 represents the photoluminescence spectrum of the $\mathrm{ZnO}$ hollow spheres obtained with an excitation wavelength of $325 \mathrm{~nm}$. ZnO hollow spheres exhibit a strong emission at $422 \mathrm{~nm}$ with three weak emissions at 400,484 and $529 \mathrm{~nm}$. The UV emission at $400 \mathrm{~nm}$ is attributed to the near-band-edge emission of $\mathrm{ZnO}$, originating from the excitonic transitions between the electrons in the conduction bands and the holes in the valence bands (VB) [35]. It is known that visible luminescence mainly originates from defect states such as $\mathrm{Zn}$ interstitials $\left(\mathrm{Zn}_{\mathrm{i}}\right)$ and oxygen vacancies. The strong emission peak centered at $422 \mathrm{~nm}$ can be assigned to the recombination of an electron at $Z n_{i}$ and a hole in the 


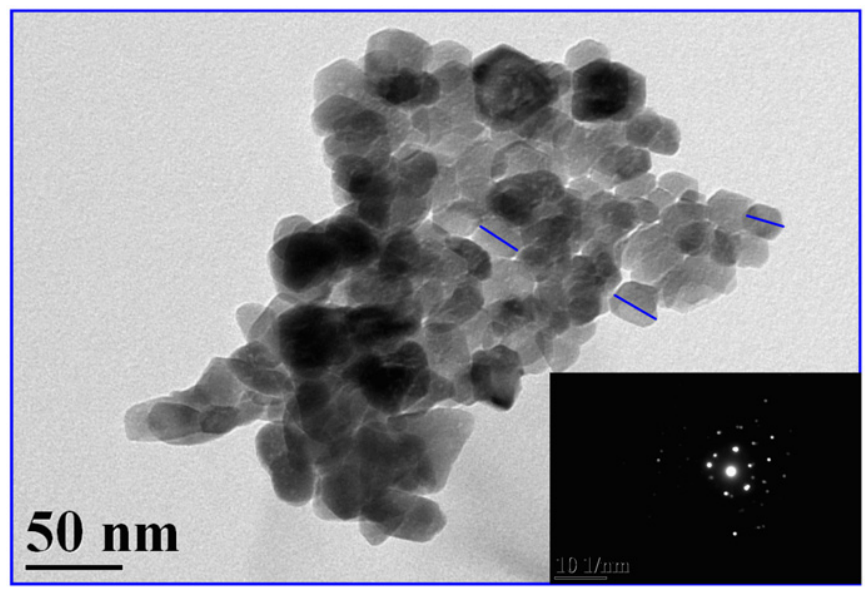

Fig. 4. TEM image and SAED pattern (inset) of the $\mathrm{ZnO}$ products prepared at $160{ }^{\circ} \mathrm{C}$.

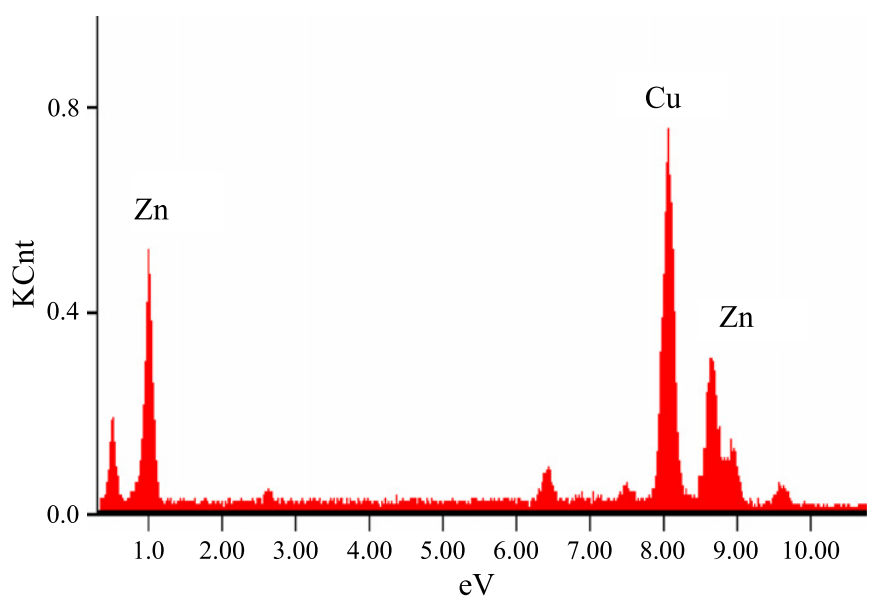

Fig. 5. EDS spectrum of $\mathrm{ZnO}$ product prepared at $160{ }^{\circ} \mathrm{C}$ for $1 \mathrm{~d}$.

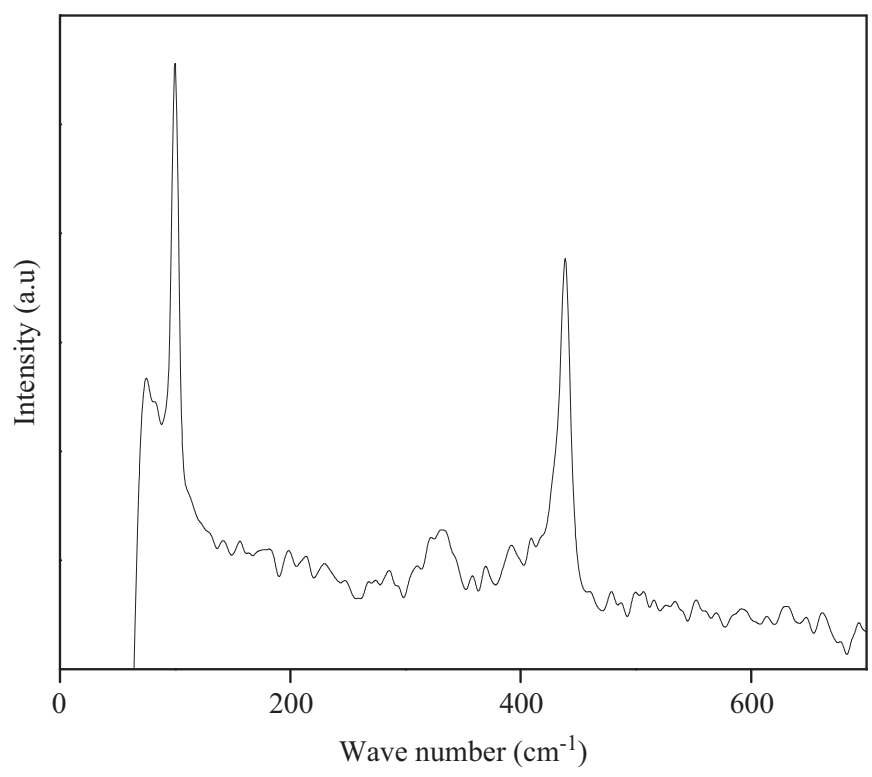

Fig. 6. Raman spectrum of $\mathrm{ZnO}$ hollow spheres prepared at $160{ }^{\circ} \mathrm{C}$ for $1 \mathrm{~d}$.

valence band. The weak emission peak around $530 \mathrm{~nm}$ may be related to the singly ionized oxygen vacancy [43] and the mechanism of the emission at $485 \mathrm{~nm}$ is not yet clear. The

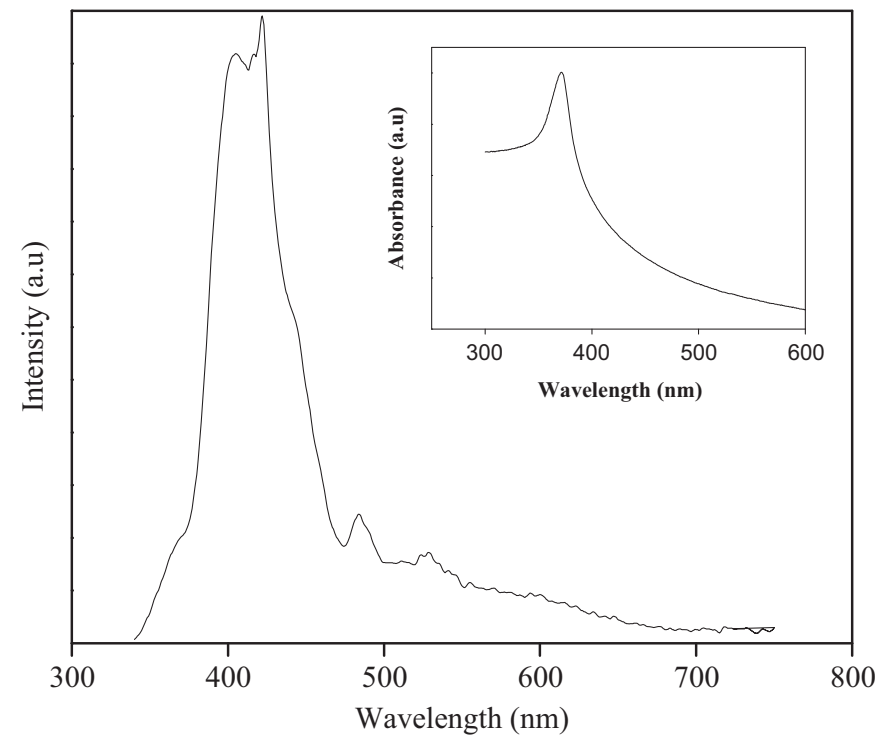

Fig. 7. Room temperature PL spectrum of $\mathrm{ZnO}$ products. The inset is the UV-vis absorption spectrum of $\mathrm{ZnO}$ products prepared at $160{ }^{\circ} \mathrm{C}$ for $1 \mathrm{~d}$.

absorption peak centered for $378 \mathrm{~nm}$ can be clearly observed (inset of Fig. 7). The corresponding value of direct optical band gap is found to be $3.40 \mathrm{eV}$. This value is quite comparable to the earlier reported value of $3.32 \mathrm{eV}$ for $\mathrm{ZnO}$ nanoparticles [44].

\subsection{Growth mechanism}

Once the zinc acetate is dissolved in ethylene glycol and subjected to solvothermal treatment, the following series of reactions take place: (i) First, zinc acetate dihydrate undergoes dehydration with the formation of anhydrous zinc acetate and water with the removal of coordinate water molecules:

$\mathrm{Zn}\left(\mathrm{CH}_{3} \mathrm{COO}\right)_{2} \cdot 2 \mathrm{H}_{2} \mathrm{O} \rightarrow \mathrm{Zn}\left(\mathrm{CH}_{3} \mathrm{COO}\right)_{2}+2 \mathrm{H}_{2} \mathrm{O}$

(ii) The formed anhydrous zinc acetate undergoes hydrolysis with dissociated water molecules (in the previous step) to form basic zinc acetate according to the Eq. (2). (iii) Basic zinc acetate solution is boiled continuously for several hours, acetic acid will evaporate off and only pure basic zinc hydroxide is left behind in the process as shown in Eq. (3). (iv) Finally, $\mathrm{ZnO}$ is obtained by dehydration of zinc hydroxide according to the Eq. (4) [45]:

$\mathrm{Zn}\left(\mathrm{CH}_{3} \mathrm{COO}\right)_{2}+\mathrm{H}_{2} \mathrm{O} \rightarrow \mathrm{Zn}(\mathrm{OH})\left(\mathrm{CH}_{3} \mathrm{COO}\right)+\mathrm{CH}_{3} \mathrm{COOH}$

$\mathrm{Zn}(\mathrm{OH})\left(\mathrm{CH}_{3} \mathrm{COO}\right)+\mathrm{H}_{2} \mathrm{O} \rightarrow \mathrm{Zn}(\mathrm{OH})_{2}+\mathrm{CH}_{3} \mathrm{COOH}$

$\mathrm{Zn}(\mathrm{OH})_{2} \rightarrow \mathrm{ZnO}+\mathrm{H}_{2} \mathrm{O}$

The formation mechanism of $\mathrm{ZnO}$ hollow spheres in zinc acetate-ethylene glycol system was investigated. We speculate that ethylene glycol may not only be the solvent but also act as a crystal growth modifier. It is difficult to obtain the spherical $\mathrm{ZnO}$ structure without the help of spherical template owing to its different growth rates of $\mathrm{ZnO}$ crystal in different directions [46]. Ethylene glycol serves as growth inhibitor due to presence of two functional hydroxyl (-OH) groups [36]. The two hydroxyl groups present at both ends could effectively attach to the $\left(\begin{array}{llll}0 & 0 & 0 & 1\end{array}\right)$ surface of $\mathrm{ZnO}$ crystals due to slightly positive charged $\mathrm{Zn}$ surface [36]. In addition to this, the hydroxyl groups of ethylene glycol could also form hydrogen bonds with the negatively charged $\left(\begin{array}{llll}1 & 0 & 1 & 0\end{array}\right)$ and $\left(\begin{array}{llll}0 & 1 & 1 & 0\end{array}\right)$ planes of $\mathrm{ZnO}$ [47]. These surface interactions can inhibit the growth of the $\mathrm{ZnO}$ crystals in all directions and help the formation of $\mathrm{ZnO}$ nanoparticles. The formed $\mathrm{ZnO}$ 


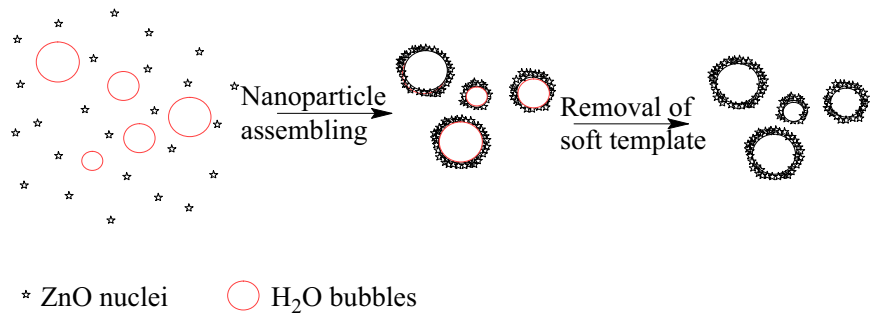

Fig. 8. Schematic illustration of the possible formation mechanism of $\mathrm{ZnO}$ hollow spheres.

nanoparticles have tendency to aggregate around the gas liquid interface (water bubbles) due to their high surface energy. Finally, they emerge as hollow spheres. The overall schematic representation of growth process for the hollow spheres is shown Fig. 8.

\section{Conclusion}

In summary, we have demonstrated a simple solvothermal approach to synthesize hollow structured $\mathrm{ZnO}$ microspheres. Ethylene glycol plays a vital role for the formation of hollow spheres by controlling the growth of $\mathrm{ZnO}$ crystals during solvothermal condition. This simple and novel method can be adopted for the preparation of other metal oxides hollow structure.

\section{Acknowledgments}

The authors are thankful to the Department of Science and Technology, Government of India, New Delhi, for the financial support given to carry out the research.

\section{References}

[1] M.E. Davis, Nature 417 (2002) 813.

[2] F. Caruso, Advanced Materials 13 (2001) 11.

[3] S.W. Kim, M. Kim, W.Y. Lee, T. Hyeon, Journal of the American Chemical Society 124 (2002) 7642

[4] S. Park, J.H. Lim, S.W. Chung, C.A. Mirkin, Science 303 (2004) 348.

[5] D. Grosso, C. Boissiere, C. Sanchez, Nature Materials 6 (2007) 572.

[6] T.K. Maji, R. Matsuda, S. Kitagawa, Nature Materials 6 (2007) 142.

[7] M.S. Sander, M.J. Cote, W. Gu, B.M. Kile, C.P. Tripp, Advanced Materials 16 (2004) 2052.

[8] S. Wang, H. Xu, L. Qian, X. Jia, J. Wang, Y. Liu, W. Tang, Journal of Solid State Chemistry 182 (2009) 1088.

[9] J.J. Teo, Y. Chang, H.C. Zeng, Langmuir 22 (2006) 7369.
[10] H.G. Yu, J.G. Yu, B. Cheng, S.W. Liu, Nanotechnology 18 (2007) 065604.

11] Q. Cao, Y. Gao, X. Chen, L. Mu, W. Yu, Y. Qian, Chemistry Letters 35 (2006) 178.

[12] X.M. Liu, W.D. Yin, S.B. Miao, B.M. Ji, Materials Chemistry and Physics 113 (2009) 518.

[13] J. Park, X. Shen, G. Wang, Actuators B 136 (2009) 494

[14] Y. Wang, Q.S. Zhu, H.G. Zhang, Chemical Communications 41 (2005) 5231

15] B. Li, G. Rong, Y. Xie, L. Huang, C. Feng, Inorganic Chemistry 45 (2006) 6404

[16] X.L. Yu, Y. Wang, H.L.W. Chan, C.B. Cao, Microporous and Mesoporous Materials 118 (2009) 423

[17] X.B. Cao, L. Gu, L. Zhuge, W.J. Gao, W.C. Wang, S.F. Wu, Advanced Functional Materials 16 (2006) 896.

[18] W.S. Wang, L. Zhen, C.Y. Xu, W.Z. Shao, Crystal Growth and Design 9 (2009) 1558.

[19] J.H. Huang, L. Gao, Journal of the American Ceramic Society 89 (2006) 3877

[20] H. Zhou, T. Fan, D. Zhang, Microporous and Mesoporous Materials 100 (2007) 322.

[21] X.X. Lin, Y.F. Zhu, W.Z. Shen, Journal of Physical Chemistry C 113 (2009) 1812.

[22] Z. Deng, M. Chen, G. Gu, L. Wu, Journal of Physical Chemistry B 112 (2008) 16.

[23] P.X. Gao, Z.L. Wang, Journal of the American Chemical Society 125 (2003) 11299.

[24] G. Shen, Y. Bando, C.J. Lee, Journal of Physical Chemistry B 109 (2005) 10578

[25] H. Lu, L. Liao, J. Li, D. Wang, H. He, Q. Fu, L. Xu, Y. Tian, Journal of Physical Chemistry B 110 (2006) 23211.

[26] K.M. Sulieman, X.T. Huang, J.P. Liu, M. Tang, Nanotechnology 17 (2006) 4950

[27] Y. Zhang, W.F. Zhang, H.W. Zheng, Scripta Materialia 57 (2007) 313.

[28] P. Lipowsky, M. Hirscher, R.C. Hoffmann, J. Bill, F. Aldinger, Nanotechnology 18 (2007) 165603.

[29] Y. Yang, Y. Chu, Y.P. Zhang, F.Y. Yang, J.L. Liu, Journal of Solid State Chemistry 179 (2006) 470.

[30] Y. He, Materials Letters 59 (2005) 114.

[31] H.T. Schmidt, A.E. Ostafin, Advanced Materials (Weinheim, Germany) 14 (2002) 532.

[32] Y. Xie, J. Huang, B. Li, Y. Liu, Y. Oian, Advanced Materials 12 (2000) 1523

[33] Z. Chen, L. Gao, Crystal Growth and Design 8 (2008) 460

[34] E. Hosono, S. Fujihara, T. Kimura, H. Imai, Journal of Sol-Gel Science and Technology 29 (2004) 71.

[35] S. Ashoka, G. Nagaraju, C.N. Tharamani, G.T. Chandrappa, Materials Letters 63 (2009) 873

[36] S. Kunjara, N. Ayudhya, P. Tonto, O. Mekasuwandumrong, V. Pavarajarn, P. Praserthdam, Crystal Growth and Design 6 (2006) 2446.

[37] L. Poul, N. Jouini, F. Fiévet, Chemistry of Materials 12 (2000) 3123.

[38] J. Miao, M. Xue, H. Itoha, Q. Feng, Journal of Materials Chemistry 16 (2006) 474.

[39] C. Liang, Y. Shimizu, M. Masuda, T. Sasaki, N. Koshizaki, Chemistry of Materials 16 (2004) 963.

[40] J.W. Lee, W.C. Choi, J.D. Kim, Crystal Engineering Communications 12 (2010) 3249.

[41] W.L. Lee, R.L. Yong, Applied Physics Letters 69 (1996) 526

[42] T.C. Damen, S.P.S. Porto, B. Tell, Physical Review 142 (1966) 570.

[43] P. Jiang, J.J. Zhou, H.F. Fang, C.Y. Wang, Z.L. Wang, S.S. Xie, Advanced Functional Materials 17 (2007) 1303.

[44] X. Han, R. Liu, W. Chen, Z. Xu, Thin Solid Films 516 (2008) 4025.

[45] H. Bahadur, A.K. Srivastava, R.K. Sharma, S. Chandra, Nanoscale Research Letters 2 (2007) 469.

[46] Y.F. Zhu, D.H. Fan, W.Z. Shen, Journal of Physical Chemistry C 111 (2007) 18629.

[47] B. Zhao, H. Chen, Materials Letters 61 (2007) 4890. 